\title{
New Insights into Organization Structure and Business Process: An Integrative Point of View
}

\author{
Sijia Wang1, Xiaoyong Zhou ${ }^{2}$ \\ ${ }^{1}$ The College of Management, Jinan University, Guangzhou, China \\ ${ }^{2}$ Hengzhuo Consulting Company, Shenzhen, China \\ Email: helenwang128@163.com
}

How to cite this paper: Wang, S.J. and Zhou, X.Y. (2019) New Insights into Organization Structure and Business Process: An Integrative Point of View. Open Journal of Business and Management, 7, 1953-1961. https://doi.org/10.4236/ojbm.2019.74134

Received: September 27, 2019

Accepted: October 14, 2019

Published: October 17, 2019

Copyright () 2019 by author(s) and Scientific Research Publishing Inc. This work is licensed under the Creative Commons Attribution International License (CC BY 4.0).

http://creativecommons.org/licenses/by/4.0/

\begin{abstract}
Organization structure and business process have been subjected to management study and practice for decades. However, the relationship between them is a topic that has received only limited and fragmented theoretical treatment. This paper proposes an integrative view with the utilization of a new emergent theory, namely the total relationship flow management theorems. We conclude that organization structure and business process are both governed by the total relationship flows, which may shed a new light on related discussions.
\end{abstract}

\section{Keywords}

Organization Structure, Business Process, Total Relationship Flow

Management, Organizational Performance, Organization Management

\section{Introduction}

The effort of managers aims at leading the organization to achieve the desired behaviors [1], e.g. production behavior, sales behavior, profit-making behavior, etc. Therefore, the fundamental issue of organization and management research is what governs the behavior of an organization. If the problem is accurately resolved, managers could effectively manage the organizational behavior by purposefully managing the determinants; otherwise, due to insufficient understanding of organization, managers' efforts are inevitably blind and less efficient.

Many scholars have worked hard to study the factors related to organizational performance. Prevailing views tend to attribute it to two main factors, i.e. organization structure and business process. Organization theory places the organization structure in a critical position. As Sterman (2000) noted, this belief is based on the widely acknowledged systematic view that system functions are de- 
termined by system structures and external environment [2]. Similarly, organization, as a special type of system including people, its behavior is also influenced by the organizing structure. The influence of such structure, while not as apparent as that of other physical systems like a building or an atom, is assumed to be persuasive. Many researchers have devoted their efforts to empirical studies and simulation experiments to ascertain such relationships, e.g. Dalton (1980) summarizes the literature addressing the empirical evidence between organization structure and performance [3], Dignum (2005) assumes that reorganization of the structure of an organization is a crucial issue to enhance task performance in an open and dynamic environment [4], Csaszar (2012) develops and tests a model of how organizational structure influences organizational performance using evidence from mutual funds [5].

From a distinctive aspect, business process, first described by Davenport and Short (1990) [6] and Hammer (1990) [7], has also been concerned closely with organizational performance. The BPR theory contends that managers should use the power of modern information technology to redesign and reorganize the business processes in order to find imaginative new ways to accomplish work and achieve dramatic improvements in their performance. There has been much available process modeling techniques and corresponding tools to provide general analysis and optimization of business processes, such as SysML, UML, IDEF*, petri-net, BPMN, etc. [8] [9] [10].

Though a surge of papers and practitioners have shown their interest in whether structure or process affects organizational performance respectively, little research has addressed the issue of how this happens and the exact relationship between structure and process. For a long time, they are viewed as two independent research domains in management. As a consequence, the field of crossing research is currently disorganized, without a possibility to lucubrate. Nevertheless, since both organization structure and business process are considered as determinants of organizational behaviors, there must exist certain linkages or common attributes which make them work as expected. The present lack of knowledge regarding the operating laws of organizations has largely restricted the practical progress. Numerous results show that many efforts devoted to organization structure design and business process management tend to be in vain and fail to meet managers' expectations.

This paper attempts to provide further insights on management by investigating the relation between structure and process. A new theory, namely the total relationship flow management theorems, is introduced to bridge the gaps from the angel of relationships of the elements. The paper is organized as follows. First, the need to further examine structure and process is established based on literature reviews. Second, a brief introduction to the total relationship flow management theorems is presented. Third, further explanations of structure and process grounded on the above theorems are given. Finally, main implications and further research possibilities are discussed. 


\section{Literature Review}

\subsection{Organization Structure}

Most managers are facing the problem how to organize an organization. Organization structure is considered as the anatomy of the organization, providing a foundation within which the organization functions. Despite "structure" is one of the most important terms in the vocabulary of current social science, researchers find it nearly impossible to define it adequately [11].

Generally, organizational structure is defined as the enduring characteristics of an organization reflected by the distribution of units and positions and their systematic relationships to each other [12]. Mintzberg (1980) claimed that organizational structuring focuses on the division of labor of an organizational mission into a number of distinct tasks, and then the coordination of all these tasks to accomplish that mission in a unified way [13]. Hall (1977) suggested that structure has two basic functions. On the micro level, structures are designed to minimize or at least regulate the influence of individual variations on the organization. From the macro perspective, structure is the setting in which power is exercised, decisions are made, and the organization's activities are carried out [14]. Swell believes that it is structure that shapes people's practices but it is also people's practices that constitute and reproduce structures [11]. In a somewhat similar vein, Ranson et al. (1980) viewed the notion of organizational structure as a medium of control created by the interactions of organizational members [15]. For this reason, organizational structure is not static, but evolves with people's behavior.

In an attempt to make some sense out of the varied conceptions on structure, scholars put forward a series of common features. Campell et al. (1974) suggested a useful distinction between "structural" and "structuring" characteristics [16]. The "structural" qualities of an organization are its physical characteristics, such as size, span of control, and numbers of hierarchical levels. In contrast, "structuring" refers to policies and activities occurring within the organization that prescribe or restrict the behavior of organization members, including specialization, formalization and centralization. Some other measurements are also mentioned in other papers, e.g. degree of task interdependence, authority structure, psychological distance between decision makers and operating levels and so on [17].

However, any attempt to construct a bridge between the different conceptualizations is tenuous because of the inherent limit of empirical evidence. First, as individual characteristics could lead to various criteria in perception, almost no two studies use the same dimensions in the description of organizational structure. This might not be an unwarranted criticism if the priori structural characteristics adequately sampled the domain of organizational variables. Second, the conclusions could also be different and even contradictory due to their limited sample sizes and deficient cross validation and generalization. It's no wonder that Dalton (1980) concludes: "the literature on structure-performance relation- 
ships is the most vexing and ambiguous in the field of management and organizational behavior. It may be that, in practice, no such relationship exists between structure and performance." [3].

The differentiation of overall organizational structure into conceptually different functional and structural components has also been advocated by some authors. This includes the simple liner structure, function-based structure, matrix structure and some new forms labelled by modular organization, network organization, leaning organization and virtual organization [18] [19], which are always depicted by organizational chart. With popularization, some managers equal the organizational structure as the organization chart with boxes and lines, and the meaning behind the chart is sometimes lost. All these concepts have diffused broadly, and some practitioners have also become diffuse about why their efforts to organization structure redesign are in vain in most time.

\subsection{Business Process}

For about 40 years the classical organization theory has been a mainstream for theory construction. However, the rapid changes in economic environment has led to an increasing interest in improving organizational business process to enhance performance. Vast papers and practitioners have devoted to this area for more than a decade.

A business process is a complete, dynamically coordinated set of activities of logically related tasks that must be performed to fulfill the strategic goals [20], e.g. manufacturing, marketing, transporting and some other operations. And business process reengineering (BPR), first proposed by Hammer M. Porter, is a radical redesign of processes in order to gain significant improvement in cost, quality and service. In comparison to traditional organizational forms, process organization seems a promising way to overcome functional silos that can create barriers to effective information flow and constrain the value that can be generated by the enterprise.

Despite the significant growth of business processes and relevant concepts, not all organizations embarking on BPR projects achieve their intended result. Most reviews report as many as $60 \%-80 \%$ of BPR initiatives having actually failed or delivered less than promised [21]. It is therefore not surprising that the service industry is not convinced that a business approach could bring significant tangible and measurable benefits [22]. Responding to the resulting confusion, more recent literature suggests that the first generation of BPR, which suggests radical changes in business process, is evolving into a modest process management, which is softened by the lessons learned from successes and failures in the course of implementations. Besides, several papers tried to identify critical success factors (CSF) of BPM. For instance, Al-Masharij et al. (1999) summarized 32 successful factors and 22 failures factors relating to the implementation of BPR projects [23]. The following are almost most frequently included in the list: top management support, project management, interdepartmental cooperation and lack of training [24]. Above all, misunderstanding of the 
$\mathrm{BPM}$ concept and misapplication of this term are two of the most cited reasons of BPM failures [25]. However, those identified CSFs of BPM are often casespecific. Whether the CSFs of companies operating in one country or one industry can apply to those operating in other countries is rarely confirmed. In consequence, the academic community often criticized BPM for having no sound theoretical basis. Deakins and Makgill (1997) argues that the original literature on BPR was essentially anecdotal, lacking rigorous research to support its assertions [26]. It indicates that there is still a need to better interpret how the BPR implementations can affect organizational behavior.

Structure and process have been the topic by both theory and practice, yet people's understanding of these two essential terminologies is far from enough. Several important issues haven't been solved properly. For example, should the process be designed first or the structure first? Some scholars argue that the actual form of the organization's structure ought to be determined during the administrative phase as management establishes process for coordinating and controlling internal operations. Others believe that business process demonstrates the way in which posts are linked with each other, as a result, only when structure is designed can business process be set. In practice, the architecture chart and process flow chart are plotted simultaneously, but nobody clearly knows how to set appropriate linkages between those diagrams.

\section{Theory Ground}

Based on the concept of relationship flows and the structural theory of general systems [27] [28], Lin et al. (2007, 2013) mathematically derived three theorems, called the total relationship flow management theorems (TRFMTs) [29] [30], which open a new way to organization management. From the systematic view, the organization is defined as a whole made up of several interrelated parts. And a relationship flow $R_{i j}(t)$ of an organization is factor flow, such as material flow, capital flow, information flow, personnel flow, energy flow, etc., by which different parts of the organization interact with each other. In consequence, all the relationships between organization and external environment, as well as the relationships between internal parts of the organization, are established by the relationship flow. More importantly, a relationship flow has the so-called LTPCAMD dimensions, i.e., the level it locates in the organization, the time when it is set up or the period the relationship flow cycle goes through, the parts it connects, the contents and amount it consists, the means or manners through which it transfers and the inevitable time delay in the process. By the corollary to the theorems, the behavior of an organization is determined and governed only by the organization's input $R f(t)$ and all its relationship flows $R_{O r b}(t)$ at or

above a so-called basic level $H_{d}$, i.e. the total relationship flow $\operatorname{TRf}(t)$; especially by the relationship flow cycles in $\operatorname{TRf}(t)$.

The theory was particularly chosen as a result of the universally acknowledged limits of conventional research methods. A single case study, though efficient for 
examination of theories, is not adequate for the construction and establishment of theories because it is so case-specific that seldom generalized findings can be achieved. Empirical analysis is one of the most widely used approaches in the field of management research. But a major unanswered question is how such descriptive variables or dimensions as well as the selected samples and data may be presented to be relevant and meaningful for total organizational analysis. Besides, computer simulation is also criticized for the difficulty to extract a virtual model from a real enterprise. Such hassle may derive from the inherent complexity of the field, since management challenges span from organizational, psychological, computational and social problems. In this context, the system theory provides some new paradigms and insights and the interdisciplinary research combining the system science with organizational management seems a promising way. And the total relationship flow management theorems are exactly a bold try on this.

Due to the universality of systems and the accuracy of mathematic expressions, the total relationship flow management theorems are intentionally quite general and more scientific. It can be applied to different organizations from various industries, which exactly fixes the deficiencies of traditional methodologies. From a theoretical standpoint, the theory has provided a parsimonious mechanism to explain how micro individual behaviors are aggregated into macro organization-level performance by the relationship flows and develops management into an exact science. On the practical front, the findings highlight the fundamentals of management that should be properly considered by the companies and their managers to improve the organizational performance.

As the relationship flows have been mathematically proved to be the direct factor of organization behavior, there is bound to exist a reasonable explanation on how the organizational structure and business process are related to relationship flows to affect organizational performance. The issue would be discussed at length in the next section.

\section{Discussion}

Acknowledging the possible limitations in previous studies, it is quite necessary to reiterate the term "organizational structure" and "business process" to explore a much deeper understanding. Based on the TRFMTs, the general sense of organizational structure, more accurately, should be interpreted as "architecture", which merely indicates the hierarchical reporting lines between positions in an enterprise. It contains only limited horizontal information flows, but not all the possible relationships including capital, material, personnel, energy, etc. As to those studies concerning dimensions of descriptive structure, it is questionable that the presented categories adequately encompassed all structural variance and those neglected ones would not play a role in organizational performance. It is very dangerous to assume that simply copying either the organization architecture or the approach towards their improvement from one successful case to another will bring the same benefits. New interpretation is presented as follows. 
According to the theorems, all the relationships within organizations are established through the relationship flows. As organizational structure attempts to reveal the internal relationships, it is easily deduced that the set of relationship flows is a kind of organization structure. By this definition, organization structure is such a variable that can be precisely calculated and managed through the management of relationship flows. Of additional importance is the fact that the proposed definition of structure is based upon a mathematically proved theorems and the conclusion that "organizational structure determines organizational performance" can be verified easily.

The business processes, on the other hand, could be considered as a series of behaviors. The concept is addressed as the behavior and its hierarchy and evolutionary logic (BHEL) in the total relationship flow management research. The framework aims at describing the path to realize the predetermined strategies or objectives. It includes the hierarchical, post-hoc and chorological logic between the behaviors. However, business processes design is of critical importance but only the groundwork, while scholars seemly ignore one thing, that is, what governs the quality of business process? Based on TRFMTs, the upstream performs the actions and transfers the relationship flows to the downstream to set off its reactions. In this case, business processes are also triggered and controlled by the total relationship flows.

Thus, each of the three proposed determinants of organization behavior is not in isolation but rather as an inter-connected set. Both the structure and business process are governed by the total relationship flows. The main reason for unsuccessfulness of organizational structure design and BPM projects can thus lie in the failure to consider the evolution of relationship flows and the variability of seven dimensions. In the old paradigm, managers attempt to manage items such as boxes on the organization chart or the business process diagram. In the new world, all influence is based on the tangible and intangible relationship flows. Managers are able to shape organizational performance by setting up its appropriate TRF for the behavior and to eliminate undesired behavior by rearranging the appropriate TRF for the behavior, which is more targeted and efficient.

\section{Conclusion}

Our study represents an initial attempt: 1) to portray the vagueness and contradiction of available studies on structure and process and put forward the requirement for further discussions, 2) to provide a common language for discussing organization structure and business process from the perspective of total relationship flows. The paper offered integrated considerations regarding the issue of organizational performance and a consistent conclusion is achieved. The total relationship flows are the direct factors to govern the responding behavior and the structure and processes are both related to the relationship flows. Hence, future research and practice on organization structure design and business process management can be explored in a much more scientific and direct manner. This can facilitate the difficult process of realizing an expected organizational objec- 
tive. However, we begin at the beginning. The argument would be far more convinced if it were built on more applications in practice. More empirical research and case studies are supposed to be carried out.

\section{Conflicts of Interest}

The authors declare no conflicts of interest regarding the publication of this paper.

\section{References}

[1] Argote, L. and Greve, H.R. (2007) A Behavioral Theory of the Firm-40 Years and Counting: Introduction and Impact. Organization Science, 18, 337-349. https://doi.org/10.1287/orsc.1070.0280

[2] Sterman, J.D. (2000) Business Dynamics: Systems Thinking and Modeling for A Complex World. Mcgraw-Hill Companies, New York.

[3] Dalton, D.R., Todor, W.D. and Spendolini, M.J. (1980) Organization Structure and Performance: A Critical Review. Academy of Management Review, 5, 49-64. https://doi.org/10.5465/amr.1980.4288881

[4] Dignum, F., Dignum, V. And Sonenberg, L. (2005) Exploring Congruence Between Organizational Structure and Task Performance: A Simulation Approach. International Conference on Autonomous Agents and Multiagent Systems, Berlin, 213-230. https://doi.org/10.1007/11775331_15

[5] Csaszar, F.A. (2012) Organizational Structure as a Determinant of Performance: Evidence from Mutual Funds. Strategic Management Journal, 33, 611-632. https://doi.org/10.1002/smj.1969

[6] Davenport, T.H. and James E.S. (1990) The New Industrial Engineering: Information Technology and Business Process Redesign. Sloan Management Review, 31, 11-27.

[7] Hammer, M. (1990) Reengineering Work: Don't Automate, Obliterate. Harvard Business Review, 68, 104-112.

[8] Bock, C. (2006) SysML and UML 2 Support for Activity Modeling. Systems Engineering, 9, 160-186. https://doi.org/10.1002/sys.20046

[9] Bosilj-Vuksic, V., Giaglis, G.M. and Hlupic, V. (2001) IDEF Diagrams and Petri Nets for Business Process Modeling: Suitability, Efficacy, and Complementary Use. In: Sharp, B., Filipe, J. and Cordeiro, J., Eds., Enterprise Information Systems II, Springer Press, Dordrecht, 143-148. https://doi.org/10.1007/978-94-017-1427-3_21

[10] Dijkman, R.M., Dumas, M. and Ouyang, C. (2008) Semantics and Analysis of Business Process Models in BPMN. Information and Software Technology, 50, 1281 1294. https://doi.org/10.1016/j.infsof.2008.02.006

[11] Sewell, W.H. (1992) A Theory of Structure: Duality, Agency, and Transformation. American Journal of Sociology, 98, 1-29. https://doi.org/10.1086/229967

[12] Porter, L.W. and Lawler, E.E. (1965) Properties of Organization Structure in Relation to Job Attitudes and Job Behavior. Psychological Bulletin, 64, 23-51. https://doi.org/10.1037/h0022166

[13] Mintzberg, H. (1980) Structure in 5's: A Synthesis of the Research on Organization Design. Management Science, 26, 322-341. https://doi.org/10.1287/mnsc.26.3.322

[14] Hall, R.H. (1977) Organizations: Structure and Process. Prentice-Hall, Englewood Cliffs, NJ. 
[15] Ranson, S., Hinings, B. and Greenwood, R. (1980) The Structuring of Organizational Structures. Administrative Science Quarterly, 25, 1-17. https://doi.org/10.2307/2392223

[16] Campbell, J.P., Bownas, D.A. and Peterson, N.G. (1974) The Measurement of Organizational Effectiveness: A Review of Relevant Research and Opinion. Personnel Decisions Research Institute, Minneapolis, $\mathrm{MN}$.

[17] Indik, B.P. (1968) Toward and Effective Theory of Organizational Behavior. Personnel Administration, 31, 51-57.

[18] Peter, S. (1990) The Leader's New Work: Building Learning Organizations. Sloan Management Review, 32, 7-23.

[19] Miles, R.E. and Snow, C.C. (1986) Organizations: New Concepts for New Forms. California Management Review, 28, 62-73. https://doi.org/10.2307/41165202

[20] Strnadl, C.F. (2006) Aligning Business and It: The Process-Driven Architecture Model. Information Systems Management, 23, 67-77. https://doi.org/10.1201/1078.10580530/46352.23.4.20060901/95115.9

[21] Abdolvand, N., Albadvi, A. And Ferdowsi, Z. (2008) Assessing Readiness for Business Process Reengineering. Business Process Management Journal, 14, 497-511. https://doi.org/10.1108/14637150810888046

[22] Vergidis, K., Turner, C.J. and Tiwari, A. (2008) Business Process Perspectives: Theoretical Developments vs. Real-World Practice. International Journal of Production Economics, 114, 91-104. https://doi.org/10.1016/j.ijpe.2007.12.009

[23] Al-Mashari, M. andZairi, M. (1999) BPR Implementation Process: An Analysis of Key Success and Failure Factors. Business Process Management Journal, 5, 87-112. https://doi.org/10.1108/14637159910249108

[24] Ariyachandra, T.R. and Frolick, M.N. (2008) Critical Success Factors in Business Performance Management-Striving for Success. Information Systems Management, 25, 113-120. https://doi.org/10.1080/10580530801941504

[25] Attaran, M. (2004) Exploring the Relationship between Information Technology and Business Process Reengineering. Information \& Management, 41, 585-596. https://doi.org/10.1016/S0378-7206(03)00098-3

[26] Deakins, E. and Makgill, H.H. (1997) What Killed BPR? Some Evidence from the Literature. Business Process Management Journal, 3, 81-107. https://doi.org/10.1108/14637159710161594

[27] Lin, F. and Cheng, T.C.E. (1998) The Structural Model of General Systems and its Proof. Official Journal of the World Organization of System and Cybernetics. Kybernetes, 27, 1062-1074. https://doi.org/10.1108/03684929810246099

[28] Lin, F. andCheng, T.C.E. (1999) The Principles and Laws of General Systems and Their Applications. Official Journal of the World Organization of System and Cybernetics. Kybernetes, 28. https://doi.org/10.1108/k.1999.06728aaf.001

[29] Lin, F. and Cheng,T. C.E. (2007) The Structural Theory of General Systems Applied in Management: The Total Relationship Flow Management Theorems. International Journal of General Systems, 36, 673-681. https://doi.org/10.1080/03081070701265216

[30] Lin, F., Cheng, T.C.E. and Huang, C. (2013) Developing an Organization Design Framework and Sample Based on the Total Relationship Flow Management Theorems. IEEE Transactions on Systems, Man, and Cybernetics: Systems, 3, 1466-1476. https://doi.org/10.1109/TSMC.2013.2252894 